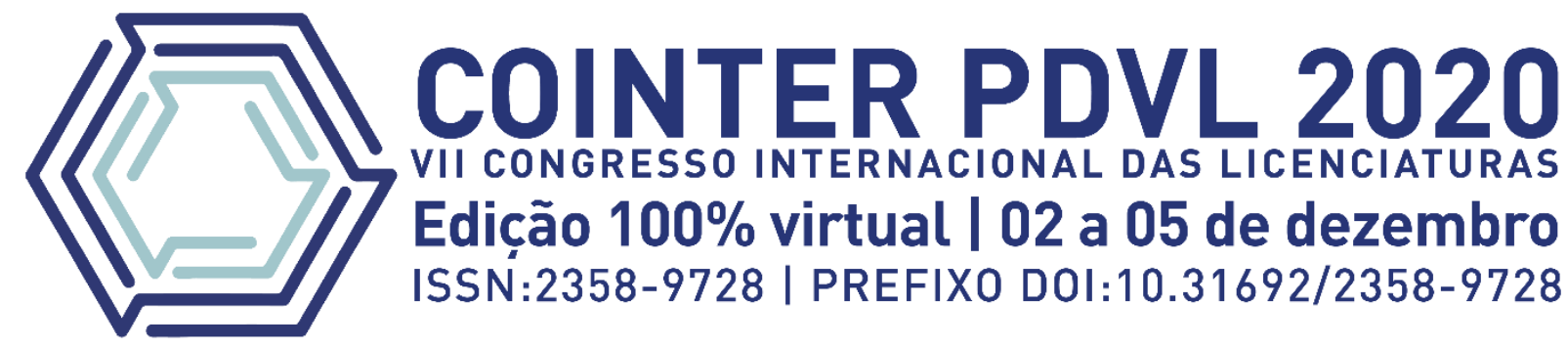

\title{
CONHECIMENTO DOS PROFISSIONAIS NA EDUCAÇÃO INFANTIL SOBRE PRIMEIROS SOCORROS: REVISÃO DE LITERATURA
}

\section{CONOCIMIENTO DE PROFESIONALES EN EDUCACIÓN INFANTIL SOBRE PRIMEROS AUXILIOS: REVISIÓN DE LA LITERATURA}

\section{KNOWLEDGE OF PROFESSIONALS IN CHILD EDUCATION ABOUT FIRST AID: A LITERATURE REVIEW}

\author{
Apresentação: Comunicação Oral \\ Danielle Jaqueline da Silva ${ }^{1}$; Tatiana Peres Santana Porto Wanderley ${ }^{2}$; Márcia Pessoa de Souza Noronha ${ }^{3}$; \\ Anselmo Cordeiro de Souza ${ }^{4}$; Simone Sampaio da Costa ${ }^{5}$
}

DOI: https://doi.org/10.31692/2358-9728.VICOINTERPDVL.0297

\begin{abstract}
RESUMO
Definem-se como primeiros socorros as condutas iniciais que objetivam ajudar pessoas que estejam em sofrimento ou risco de morte e que qualquer pessoa, mesmo que não seja profissional de saúde, pode realizar. O presente estudo discutiu o conhecimento dos profissionais na Educação Infantil sobre primeiros socorros. O objetivo deste estudo foi identificar o conhecimento dos primeiros socorros dos docentes que atuam na área da educação infantil. Os objetivos específicos foram identificar os principais acidentes que ocorrem no âmbito escolar e descrever as condutas realizadas pelos educadores no momento da ocorrência. Trata-se de revisão narrativa da literatura indexada de caráter exploratório e abordagem descritiva. Verificou-se que a falta de treinamento e de conhecimentos sobre a temática por parte dos educadores pode ocasionar sérios problemas, desde uma manipulação incorreta da vítima ao acionamento desnecessário das equipes de emergência ou até mesmo a morte, assim, face ao exposto, torna-se necessário à atualização dos profissionais da educação infantil, pelo menos uma vez ao ano, visto atender não apenas a obrigatoriedade da lei, mas uma atualização das práticas de primeiros socorros em constante renovação.
\end{abstract}

Palavras-Chave: Saúde escolar, Promoção da Saúde, Primeiros Socorros, Educação Infantil, Acidente.

\section{RESUMEN}

Las medidas de primeros auxilios se definen como acciones iniciales destinadas a ayudar a las personas que están sufriendo o en riesgo de muerte y que cualquier persona, aunque no sea un profesional sanitario, puede realizarlas. El presente estudio discutió el conocimiento de los profesionales de Educación Infantil sobre primeros auxilios. El objetivo de este estudio fue identificar los conocimientos en primeros auxilios de los docentes que trabajan en el campo de la educación infantil. Los objetivos específicos fueron identificar los principales accidentes que ocurren en el ámbito escolar y describir la

\footnotetext{
${ }^{1}$ Enfermeira, Centro Universitário Luterano de Palmas, daniellejs96@gmail.com

${ }^{2}$ Especialista, Centro Universitário Luterano de Palmas, tatiporto3@gmail.com

${ }^{3}$ Mestre, Centro Universitário Luterano de Palmas, marciapessoaenf@gmail.com

${ }^{4}$ Mestre, Centro Universitário Adventista de São Paulo, sicosta2000@yahoo.com.br

${ }^{5}$ Mestre, Centro Universitário Adventista de São Paulo, anselmo.vivamelhor@hotmail.com
} 
conducta realizada por los educadores en el momento del suceso. Se trata de una revisión narrativa de la literatura indexada de carácter exploratorio y enfoque descriptivo. Se encontró que la falta de capacitación y conocimiento sobre el tema por parte de los educadores puede ocasionar serios problemas, desde el manejo incorrecto de la víctima hasta la activación innecesaria de los equipos de emergencia o incluso la muerte, por lo tanto, en vista de lo anterior, es necesario actualizar a los profesionales de la educación infantil, al menos una vez al año, ya que se cumple no solo con la obligatoriedad de la ley, sino una actualización de las prácticas de primeros auxilios en constante renovación.

Palabras Clave: Salud escolar, Promoción de la salud, Primeros auxilios, Educación infantil, Accidentes.

\section{ABSTRACT}

First aid measures are defined as initial actions aimed at helping people who are suffering or at risk of death and that anyone, even if they are not a health professional, can perform them. The present study discussed the knowledge of professionals in Early Childhood Education about first aid. The aim of this study was to identify the knowledge of first aid by teachers who work in the field of early childhood education. The specific objectives were to identify the main accidents that occur in the school environment and describe the conduct performed by educators at the time of the occurrence. This is a narrative review of the indexed literature of an exploratory nature and descriptive approach. And it was found that the lack of training and knowledge on the subject by the educators can cause serious problems, from incorrect handling of the victim to the unnecessary activation of the emergency teams or even the death, therefore, in view of the above, it is necessary to update the professionals of early childhood education, at least once a year, since it meets not only the mandatory nature of the law, but an update of the first aid practices in constant renewal.

Keywords: School health, Health Promotion, First Aid, Child Education, Accident.

\section{INTRODUÇÃO}

A educação infantil é a primeira etapa da educação básica, e tem como finalidade o desenvolvimento integral da criança, tanto em seu aspecto físico, como psicológico, intelectual e social, complementando a ação da família e da comunidade. Constitui-se de espaços institucionais não domésticos que representam estabelecimentos educacionais públicos ou privados que educam e cuidam dessas crianças no período diurno, em jornada integral ou parcial, regulados e supervisionados por órgão competente do sistema de ensino e submetidos a controle social, sendo concebida em creches (maternais) e pré-escolas (jardins I e II) (REIS, 2010; LEITE, 2016).

Ritter et al. (2013) e Silva (2012) afirmam que na escola é comum acontecer pequenos acidentes com crianças em decorrência dos objetos e ambientes de recreação na hora do intervalo através de corridas, esportes e curiosidade pelo desconhecido. Esse momento os professores, bem como todo o centro de ensino, possuem papel importante no saber sobre desenvolvimento da saúde e na prevenção de acidentes entre crianças e adolescentes no âmbito escolar. 
A falta de conhecimento por parte dos profissionais pode trazer inúmeros problemas, como manipulação incorreta da vítima ou falta de preparo psicológico para atender com eficiência o acidentado. É nesse contexto que se torna importante o conhecimento sobre primeiros socorros entre professores, podendo evitar desde o chamamento desnecessário de socorro especializado até manter uma vida. Em se tratando de primeiros socorros, estes se referem a uma série de procedimentos simples com o intuito de manter vidas em situações de emergência, feitos por pessoas comuns com seus conhecimentos, até a chegada de atendimento médico especializado (FELICIO et al., 2016; RODRIGUES, 2016; SOUZA, 2013).

Existe uma busca em levar esse conhecimento não apenas para os alunos, mas para todos os membros da escola, fazendo com que ocorra uma maior disseminação do conhecimento. “Observa-se a importância de pessoas capacitadas nas escolas por meio de atividades educativas sobre a prevenção, avaliação e condutas dos funcionários em situação de emergência, pois as pessoas não têm informações específicas sobre o que fazer frente a um acidente o qual envolve atitudes simples relacionadas à prática de primeiros socorros e também os agravos que este pode causar" (FIORUC et al., 2008, p. 697).

Mesmo que pequenas, as crianças são capazes de avisar, prevenir e ajudar em vários acontecimentos, desde que tenham a orientação e ensinamento adequado, sendo necessário um frequente treinamento desde a infância, para que possam se acostumar com as técnicas corretas realizadas em alguns procedimentos de emergências, que apesar de simples podem mudar o rumo de uma vida.

Sena, Ricas, Viana (2011) afirmam que: o ambiente educacional é um espaço onde se localiza um amplo número de crianças em processo de interação e desenvolvimento, no qual se trabalha diferentes atividades esportivas. Por isso, o ambiente se torna favorável a acidentes. Logo, compreende-se que a escola é um recinto responsável pela formação de cidadãos, por isso torna-o um local propício para o aprendizado de práticas que visem à prevenção de agravamento de acidentes.

Sendo assim, diante do exposto, entende-se que as técnicas de primeiros socorros precisam ser trabalhadas nos espaços educacionais; e os educadores devem buscar estratégias através das quais as crianças possam aprender de forma simples e divertida, saindo da rotina dos conteúdos teóricos, participando de brincadeiras e demonstrações que lhes permitam conhecer as primeiras noções de prevenção de acidentes e primeiros socorros, e consequentemente saber o que fazer em situações emergenciais.

As crianças, de forma geral são mais vulneráveis e frágeis, e não conseguem distinguir uma situação de perigo, consequentemente estão mais expostas a inúmeras situações e riscos, 


\section{CONHECIMENTO NA EDUCAÇÃO INFANTIL SOBRE PRIMEIROS SOCORROS}

tais como: acidentes de transporte, quedas, queimaduras, violências, lesão autoprovocada, agressão/maus tratos, intoxicação por produtos químicos, engasgo, entre outros (OMS, 2017).

Grande parte dos acidentes poderia ser evitada. Porém, quando eles ocorrem, alguns conhecimentos simples podem diminuir o sofrimento, evitar complicações futuras e até mesmo salvar vidas. O fundamental é saber que, em situações de emergência, deve se manter a calma e ter em mente que a prestação de primeiros socorros não exclui a importância de um médico. Além disso, certificar - se de que há condições seguras o bastante para a prestação do socorro sem riscos. O objetivo do trabalho é Identificar o conhecimento dos docentes que atuam na educação infantil sobre primeiros socorros com base na literatura.

\section{METODOLOGIA}

Trata-se de revisão narrativa da literatura indexada de caráter exploratório e abordagem descritiva, e os passos de sua elaboração e organização derivaram de outros estudos (FURUKAWA et al., 2018, SOUZA et al., 2018).

As fontes de dados foram artigos e monografias encontradas nas bases de dados virtuais, LILACS (Literatura Latino-Americana e do Caribe em Ciências da Saúde); Portal CAPES (Coordenação de Aperfeiçoamento de Pessoal de Nível Superior) e Scielo (Scientific Eletronic Library Online). Através dos descritores DESC: Primeiros Socorros; Educação Infantil; Acidente. A pesquisa ocorreu nos meses de fevereiro a maio de 2019 nas bases de dados citadas, a partir de materiais acadêmicos relacionados ao tema. Com publicações dos últimos 10 anos e obedecendo aos critérios de inclusão.Foram considerados os artigos de Procedência nacional, com postagem do período de 2009 até 2019, com idioma em português.

Para examinar os materiais literários pesquisados, primeiro foi feita uma leitura criteriosa dos textos, em seguida, realizou-se a observação do conteúdo teórico de cada um deles de forma que permitiu responder todos os critérios contidos nos objetivos, como também no tema. A coleta de dados baseou-se na: identificação do artigo original dos autores; fonte de localização; análise de conteúdo.

\section{RESULTADOS E DISCUSSÃO}

Foi realizado uma pesquisa literária em artigos, manuais, monografias, dissertações e teses a partir de conhecimento dos profissionais na educação infantil sobre primeiros socorros, partindo daí múltiplas discussões sobre o assunto. Foram encontrados 20 artigos que se fizeram 
relevantes a esta revisão.

A análise dos artigos incluídos teve início objetivando à identificação da temática central abordada no estudo, ou seja, analisando-se o conhecimento dos profissionais da educação infantil sobre primeiros socorros. Após constantes leituras de textos foram estabelecidos os eixos focados na compreensão do tema em questão. Sendo assim, seguem-se os resultados agrupados em três temáticas, a saber, "conhecimento dos docentes que atuam na educação infantil sobre primeiros socorros", "acidentes que ocorrem no âmbito da educação infantil", "condutas realizadas pelos educadores no momento da ocorrência segundo a literatura".

\section{Conhecimento dos docentes que atuam na educação infantil sobre primeiros socorros}

É fato que, não só o profissional da educação infantil, mas como toda e qualquer pessoa, quando presencia uma situação que necessite de intervenção imediata por instinto queira prestar socorro, porém apenas boa vontade não basta, assim torna-se fundamental o preparo adequado para fazê-lo.

A fim de minimizar os danos, é importante a inclusão na grade curricular dos professores e cuidadores o treinamento de primeiros socorros, pois uma grande barreira enfrentada no sistema educacional brasileiro é a falta de preparo para tal feito. Assim, o desconhecimento de noções básicas de pronto atendimento é inaceitável, pois saber como prestar socorro a um acidentado de forma eficaz e imediata pode salvá-lo do óbito (RODRIGUES, 2016).

Para isso, criou-se um projeto de lei protocolado no Congresso Nacional em fevereiro de 2018, e aprovado em março do mesmo ano baseado na história do menino Lucas Begalli, que se engasgou com um lanche na escola em que estudava e faleceu por não ter recebido os primeiros socorros pelos profissionais que o conduziam. A tramitação foi rápida, e no dia 04 de setembro teve aprovação também do Senado Federal, já no dia 04 de outubro foi sancionada pela presidência da república, No 13.722 que diz "Torna obrigatória a capacitação em noções básicas de primeiros socorros de professores e funcionários de estabelecimentos de ensino públicos e privados de educação básica e de estabelecimentos de recreação infantil."

Portanto, nessa lógica, busca-se perceber a importância da educação em saúde no que tange aos primeiros socorros em âmbito escolar, se faz essencial que nos cursos de aperfeiçoamento seja trabalhado princípios básicos de primeiros socorros, o que facilitaria o pré atendimento a vítima, com isto evitando o agravamento (RITTER et al, 2013). 


\section{CONHECIMENTO NA EDUCAÇÃO INFANTIL SOBRE PRIMEIROS SOCORROS}

\section{Acidentes que ocorrem no âmbito da educação infantil.}

A princípio é importante destacar que são inúmeros os casos de acidentes aos quais as crianças e adolescentes estão expostos, onde a maior parte poderia ser evitada. Ao referirse a tal assunto, o autor Miranda Neto e seus colaboradores (2010), diz ser importante que as cuidadoras sejam bem orientadas quanto à capacidade de reconhecer situações que poderão colocar as crianças em risco, interferindo de forma a reduzir a ocorrência de acidentes garantindo a promoção do bem-estar físico e mental das crianças.

Além do investimento em políticas públicas que respondam ao desafio da redução dos acidentes, é necessário, também, que os professores e os auxiliares sejam proativos e capazes de reconhecer esses riscos, propondo soluções em tempo hábil para evitar acidentes, sequelas e óbitos. Trata-se, pois, de uma educação básica em cadeia (VIEIRA; CARNEIRO; FROTA, et al 2009).

Contudo, estudos mostram que pelo menos $90 \%$ dessas lesões poderiam ser evitadas com atitudes de prevenção. Entre os acidentes mais frequentes estão os acidentes de trânsito, afogamentos, sufocações, quedas, queimaduras, intoxicações, entre outros. A prevenção é, a principal saída para a problemática dos acidentes e por isso, ela deve ser uma cultura em nosso dia-a-dia (BARROS, 2011).

Os profissionais que trabalham na educação infantil têm a função de educar e cuidar de crianças e para isso precisam estar conscientes para reconhecer qualquer sinal de perigo. Com isso nota-se que a promoção da educação em saúde é de grande relevância para mobilizar pessoas da família e profissionais na prevenção de acidentes infantis. Essa responsabilidade está de acordo com o Artigo 196 da Constituição Federal onde lemos: “A saúde é direito de todos e dever do Estado, garantido mediante políticas sociais e econômicas que visem à redução do risco de doença e de outros agravos e ao acesso universal e igualitário às ações e serviços para sua promoção, proteção e recuperação".

Segundo a ONG Criança Segura (2012), o afogamento representa a segunda maior causa de morte e a sétima em hospitalizações, em crianças de até cinco anos. Nessa faixa etária, uma criança que está começando a andar, por exemplo, cinco centímetros de água representam um grande risco. Assim elas podem se afogar em piscinas, cisternas e até em baldes, banheiras e vasos sanitários. Somente em 2016, 913 meninas e meninos dessa faixa etária perderam suas vidas em razão desse tipo de acidente. $\mathrm{O}$ afogamento é um vilão ainda mais perigoso para as crianças de um a quatro anos de idade, pois é a causa número um de óbitos acidentais desse grupo etário. Em 2016, 407 crianças de um a quatro anos morreram em decorrência de 
afogamento.

Sabendo que as crianças passam em média um terço do dia na escola, durante um longo período de tempo, estudando e desenvolvendo sua educação, caráter, cultura e cidadania, é essencial que seus tutores se envolvam em atividades de promoção e proteção da saúde e soluções de eventos emergenciais. O ensino sobre reanimação cardiorrespiratória quando iniciado no período escolar tem grande contribuição para a diminuição da morbimortalidade decorrente ao desconhecimento sobre o assunto e o despreparo do socorrista frente a situação de emergência. Espera-se que em um futuro bem próximo a RCP faça parte da grade curricular dos alunos (TINOCO, 2014; TERASSI et al., 2015).

A média de sobrevivência nos casos de PCR é de $10 \%$ e muitas das crianças ressuscitadas sofrem danos neurológicos permanentes. Em contraste, a parada somente respiratória associa-se a taxa de sobrevivência maior do que 50\%, quando a ressuscitação imediata é providenciada e a maioria dos pacientes sobrevive neurologicamente intacta (SÃO PAULO, 2007).

Entender o que é, saber como se manifesta e como socorrer uma criança no meio de uma crise são papéis fundamentais da escola. Falta de informação e preconceito são realidades na vida de crianças com doenças neurológicas. A mais comum delas, a epilepsia, atinge cerca de $2 \%$ da população mundial, sendo que em $50 \%$ dos casos as crises têm início ainda na infância, podendo ser logo após o nascimento. Mas, embora ter epilepsia não signifique necessariamente ter qualquer atraso cognitivo ou neurológico, a falta de informação em relação à doença não resulta apenas em uma maior dificuldade de diagnóstico e tratamento, também potencializa situações de exclusão e, o que pode ser muito prejudicial ao processo de aprendizagem de uma criança (HUNGRIA, 2018).

Alguns estudos revelam que a epilepsia é um facilitador para o fracasso escolar ou para problemas de comportamento, atribuindo antecipadamente para que alunos sejam precocemente rotulados como preguiçosos, lentos, com falta de capacidade, má vontade ou inquietação", explicam Regina Silvia Alves de Lima, mestre em "Educação e Saúde da Infância e Adolescência" e conselheira de Advocacia da Associação Brasileira de Epilepsia, Maria Alice Susemihl, vice-presidente da Associação Brasileira de Epilepsia e Laura Ferreira Guilhoto, neurologista responsável pelo ambulatório de epilepsia na infância da Unidade de Pesquisas das Epilepsias da Unifesp - Universidade Federal de São Paulo.

Sabe-se que grande parte das síndromes epilépticas tem início na infância e cerca de $50 \%$ dos casos de epilepsia ocorrem em crianças menores de 5 anos de idade. Assim, além das dificuldades enfrentadas devido á própria doença, há ainda que se considerar a inabilidade de 


\section{CONHECIMENTO NA EDUCAÇÃO INFANTIL SOBRE PRIMEIROS SOCORROS}

grande parte dos gestores e educadores quanto à necessidade de lidar com tal problema e a rejeição por parte dos demais colegas de turma, o que invariavelmente prejudica o rendimento escolar da criança portadora de epilepsia. Desta forma, é necessária uma adequação da linguagem e do próprio processo de ensino/aprendizagem, preparação para lidar com as crises e amenizar a forma da comunidade escolar enxergar o problema. Ao instituir as Diretrizes Nacionais para a Educação Especial na Educação Básica, houve um avanço na perspectiva da universalização e atenção à diversidade, na educação brasileira, com a seguinte recomendação, em seu Art. $2^{\circ}$, os sistemas de ensino devem matricular todos os alunos, cabendo às escolas organizar-se para o atendimento aos educandos com necessidades educacionais especiais, assegurando as condições necessárias para a educação de qualidade para todos (ALVES, SOARES, FERREIRA, 2016; BRASIL, 2010).

A obstrução das vias aéreas por corpo estranho (OVACE) é um dos eventos presentes nos mais diversos ambientes, inclusive o escolar, que necessita de primeiros socorros, sendo ocasionada pela aspiração acidental de corpos estranhos. No contexto escolar, as crianças estão expostas a diversos meios desencadeantes de obstrução de vias aéreas e demais eventos que necessitam de primeiros socorros, fazendo-se necessário que o atendimento a essa criança seja imediato (ANDRADE et al., 2019).

Quando as condições da vítima e a idade do escolar permitirem, o socorrista deve fazer a seguinte pergunta: "Você está engasgado?". Se a vítima responder ou sinalizar afirmativamente com a cabeça, proceder de acordo com o grau desobstrução da via aérea.

- Obstrução leve: a vítima consciente, com obstrução leve, deve ser acalmada e incentivada a tossir vigorosamente, pois a tosse forte é o meio mais efetivo para remover um corpo estranho. A vítima deve ser observada atenta e constantemente, pois o quadro pode agravar-se repentinamente, evoluindo para obstrução grave das vias aéreas. Se a obstrução se mantiver leve, porém persistente, apesar da tosse vigorosa, encaminhar rapidamente o escolar para o Pronto Socorro de referência.

- Obstrução grave: o socorrista deve intervir para tentar a desobstrução das vias aéreas por meio das manobras descritas abaixo. O SAMU 192 deve ser acionado imediatamente por um segundo socorrista ou qualquer pessoa próxima (SÃO PAULO, 2007).

O trauma cranioencefálico (TCE) compreende desde as lesões do couro cabeludo até aquelas da caixa craniana (ossos do crânio) ou do seu conteúdo (o encéfalo). No ambiente escolar, as principais causas de TCE são as quedas, especialmente de lugares altos e as pancadas na cabeça, que podem ocorrer quando o escolar bate a cabeça em móveis, brinquedos do playground, parede ou porta, ou mesmo durante brincadeiras ou atividades esportivas (SÃO 
PAULO, 2007). De acordo com Miranda Neto et al (2010), a queda é responsável por altos índices de acidentes infantis e é considerada como o tipo de acidente mais comum, não intencional, mas evitável. Quanto mais alta a queda da superfície em que ocorrer maior é a probabilidade de lesões físicas e emocionais.

Sendo assim, os professores e funcionários das escolas, além do seu compromisso educacional e pedagógico, são também responsáveis em zelar pela segurança das crianças, dedicando-se a sua formação e bem estar.

\section{Condutas realizadas pelos educadores no momento da ocorrência segundo a literatura}

Segundo Cruvinel (2014) a escola é um ambiente propício a diferentes tipos de acidentes, além de brincadeiras agressivas entre os alunos que, por vezes, pode causar ferimentos e outras lesões físicas na vítima, situações que geram preocupação constante, sendo necessário que os profissionais da educação saibam como agir frente a esses eventos, como evitá-los e como prestar os primeiros socorros, procurando assim, livrar-se desses incidentes decorrentes de procedimentos inadequados, o que pode garantir um melhor prognóstico de eventuais lesões.

A pessoa não precisa ter um conhecimento técnico avançado no assunto e nem ser um socorrista profissional para ter condições de fazer uma avaliação primária da vítima e oferecer um primeiro atendimento, de modo que amenize as sequelas e não as agrave, e também aumente a chance de sobrevivência da vítima. As pessoas de um modo geral procuram agir por impulso nestas situações, pois a vontade de ajudar o próximo é grande, mas se esta ajuda não ocorrer de uma forma certa, ao invés de ajudar somente irá agravar a situação (BORBA, 2009).

Rocha (2012), por seu lado, afirma que é imprescindível que o professor tenha, no mínimo, o curso superior completo na área de educação. A pós-graduação em educação infantil e psicopedagogia também contribuem bastante. Somente aprofundando-se nos estudos para compreensão do desenvolvimento humano o professor poderá desenvolver seu trabalho com a qualidade que a educação infantil necessita.

Em relação a capacitação de primeiros socorros, nota-se que não existe na grade curricular atual dos cursos de licenciatura uma disciplina que ensine noções básicas de primeiros socorros, bem como na estrutura curricular nas redes de ensino. Dessa forma os professores não sabem como agir em situações que ponham em risco a vida e saúde dos alunos, conduzindo de forma inadequada qualquer criança vítima de pequenos acidentes ou que se apresente com outra condição patológica (SIEBENEICHLER; HAHN, 2014). 


\section{CONHECIMENTO NA EDUCAÇÃO INFANTIL SOBRE PRIMEIROS SOCORROS}

Dos vários artigos lidos não foi encontrado nenhum que retrate sobre as condutas realizadas pelos educadores, por isso foi dito anteriormente sobre a importância de saber agir frente a tais situações, assim, a fim de minimizar danos advindos da incorreta manipulação da vítima e/ou a falta de socorro imediato, visto que poderiam ser resolvidos no próprio local, fazse necessário a tentativa de melhorar a condição da vítima até que o atendimento do serviço móvel de urgência chegue e assuma. Tendo em vista a incidência crescente dos traumas e das complicações inerentes, torna-se de suma importância que sejam discutidos e ensinados métodos de prevenção e de atendimento nas escolas de nível fundamental, uma vez que a educação é um processo de construção dinâmico que requer tempo, dedicação e continuidade para sua aplicação, tornando-se necessário que se inicie desde cedo (BATISTA et al., 2016).

\section{CONCLUSÕES}

O desenvolvimento do presente estudo possibilitou uma análise da importância de capacitações para os profissionais da educação infantil no seguimento de urgência e emergência. Além disso, permitiu uma revisão para obter informações sobre conhecimento dos docentes que atuam na educação infantil sobre primeiros socorros, dos acidentes que mais ocorrem no ambiente escolar e as condutas realizadas em casos de ocorrência dos profissionais que trabalham nessa área. $\mathrm{O}$ estudo permitiu refletir sobre a triste realidade no que diz respeito a falha no primeiro atendimento ao aluno, visto que os profissionais não estão preparados para realizá-lo, sendo que o atendimento quando realizado de forma imediata pode livrar a vítima de complicações e até mesmo do óbito.

Assim, é de fundamental importância que os profissionais da educação infantil estejam em busca constante de capacitações, devido as crianças estarem continuamente reféns aos mais diversos tipos de acidentes, como demonstrado ao longo do trabalho. Ainda nesta mesma linha de considerações, vale citar o embasamento teórico científico, que teve grande contribuição para a elaboração desse projeto. Por fim, torna-se necessário a atualização dos profissionais da educação infantil, visto que agora é obrigatório por lei, pois assim como as práticas de primeiros socorros estão a todo momento se renovando, os profissionais deverão fazer o mesmo, dessa forma, terão eficácia nos cuidados com as crianças e saberão como agir de forma correta ao se deparar com situações de emergência.. 


\section{REFERÊNCIAS}

ALVES, P. P.; SOARES, A. W. A.; FERREIRA, M. A. Ressuscitação cardiopulmonar na escola: uma ação da liga acadêmica de emergências clínicas do amazonas (LAEC-AM). Extensão em Revista, Amazonas, v. 1, n. 1, p.1-6, 2016. Disponível em: <http://periodicos.uea.edu.br/index.php/extensaoemrevista/article/view/600>. Acesso em: 20 de out. 2018.

ANDRADE, F. T. et al. Ensino de Primeiros Socorros em OVACE em Escola Particular do Interior de Sergipe: relato de experiência. Conenf: Congresso Nacional de Enfermagem, Sergipe, $2019.1-3, \quad$ Disponível em: <https://eventos.set.edu.br/index.php/conenf/article/view/9435>. Acesso em: 20 de out. 2018.

BRASIL. Ministério da Educação. Secretaria de Educação Básica. Diretrizes curriculares nacionais para a educação infantil. Brasília: MEC/SEB, 2010. Disponível em: $<$ http://portal.mec.gov.br/index.php?option=com_docman\&view=download\&alias=9769diretrizescurriculares-2012\&Itemid=30192> Acesso em: 20 de out. 2018.

SÃO PAULO. Secretaria da Saúde. CODEPPS. Manual de prevenção de acidentes e primeiros socorros nas escolas. São Paulo: SMS, 2007. Disponível em: <https://www.amavi.org.br/arquivo/colegiados/codime/2016/Primeiros_Socorros_Manual_Pr ev_Acid_Escolas.pdf>. Acesso em: Acesso em: 20 de out. 2018.

CRIANÇA SEGURA (Organização Não Governamental). Prevenção de Acidentes com crianças. Governo do Brasil, 2012. Disponível em: <https://criancasegura.org.br/ $>$. Acesso em: 20 de out. 2018

\section{BARROS, L.S. Prevenção de Acidentes em um Centro de Educação Infantil de}

Araguaína-TO. Programa Nacional Escolas de Gestores da Educação Básica. Curso de PósGraduação Lato Sensu em Coordenação Pedagógica. Universidade Federal do Tocantins. Araguaína, 2011. <https://revistainterdisciplinar.uninovafapi.edu.br/index.php/revinter/article/view/923 >. Acesso em: 20 de out. 2018.

BORBA, C.E. Como Agir em Situações de Emergência. CEBMSC. Santa Catarina, 2009. Disponível em: < https://www.iped.com.br/materias/enfermagem/agir-caso-emergencia.html>. Acesso em: 20 de out. 2018

BATISTA, R.C. et al. SAMU na escola - a prevencão como forma de ensinar a cuidar. Ciencia saúde. $2016 . \quad$ Disponível em: <https://editorarealize.com.br/revistas/conbracis/trabalhos/trabalho_ev055_md1_sa7_id231_2 7032016211308.pdf>. Acesso em: Acesso em: 20 de out. 2018.

CRUVINEL, H. Projeto De Lei: Torna obrigatório o curso de prevenção de Acidentes e primeiros socorros em todas as escolas e creches públicas em todo o Território brasileiro. 2014. Disponível em: <http://www.camara.gov.br/proposicoesWeb/prop_mostrarintegra?codteor=1247823>. Acesso em: 20 de out. 2018. 
FELÍCIO, et al. O conhecimento de primeiros socorros para o professor de Educação Física escolar. Revista Digital. Buenos Aires, Año 20, $\mathrm{N}^{\mathrm{o}}$ 214, 2016. Disponível em: <http://www.efdeportes.com/efd214/primeiros-socorros-para-educacao-fisica-escolar.htm >. Acesso em: 20 de out. 2018.

FIORUC, B. E. et al. Educação em saúde: Abordando primeiros socorros em escolas públicas no interior de São Paulo. Rev. Eletr. Enf. 2008. Disponível em: $<$ https://www.fen.ufg.br/revista/v10/n3/pdf/v10n3a15.pdf >. Acesso em: Acesso em: $20 \mathrm{de}$ out. 2018.

FURUKAWA, M. S. A.; PITANGA, F. S. M.; MIRANDA, M. K. V.; SOUZA, A. C. Auditoria de enfermagem e tomada de decisão no controle da qualidade da assistência. Revista Interdisciplinar de Promoção da Saúde, v. 1, n. 3, p. 214-220, 2018.

HUNGRIA, C. Epilepsia na escola: como acolher e educar para a inclusão? Portal_lunetas, São Paulo - Sp, p.1-7, 09 maio 2018. Disponível em: <https://lunetas.com.br/epilepsia-naescola-como-acolher-e-educar-para-a-inclusao/>. Acesso em: 20 de out. 2018.

LEITE, G. A importância da educação infantil. Portal Administradores, João Pessoa, p.1-3, 16 jun. $2016 . \quad$ Disponível em: $<$ https://www.pedagogia.com.br/artigos/desenvolvimentodacrianca/index.php?pagina=3 .

Acesso em: 20 de out. 2018.

MIRANDA NETO, C. et al. Risco de acidentes na infância em uma creche comunitária de Ipatinga/MG. Revista Enfermagem Integrada, Ipatinga, v.3, n.1, julho-agosto, 2010.2 Disponível em: $<$ https://www.unileste.edu.br/enfermagemintegrada/artigo/v3/02-risco-acidentes-infanciacreche.pdf $>$. Acesso em: 20 de out. 2018.

OMS. Organização Mundial da Saúde: Relatório mundial de afogamentos. 2017. Disponível em :<http://radarprimeirainfancia.org.br/oms-relatorio-mundial-de-afogamentos/>. Acesso em 25 de out. 2017.

REIS, I. Manual de Primeiros Socorros: Situações de Urgência nas escolas, jardins de infância e campos de férias. Lisboa, Portugal: Ministerio da Educação, 2010. Disponível em: $<$ https://www.dge.mec.pt/sites/default/files/Esaude/primeirossocorros.pdf >. Acesso em: $20 \mathrm{de}$ out. 2018.

RITTER, N. S. et al. importância De se trabalhar o conhecimento de socorros em âmbito escolar. 2013. Disponível em: $<$ https://home.unicruz.edu.br/mercosul/pagina/anais/2013/saude/artigos/a\%20importancia\%20 de $\% 20$ se $\% 20$ trabalhar $\% 20 \mathrm{o} \% 20$ conhecimento $\% 20 \mathrm{de} \% 20$ socorros $\% 20 \mathrm{em} \% 20$ ambito $\% 20$ esc olar..pdf>. Acesso em: 20 de out. 2018.

ROCHA, L.C.S.S. Formação de Professores na Educação Infantil. Revista Projeção e Docência. $\quad$ V.3. $\quad \mathrm{N}^{\circ}$ 1. Brasília, $2012 . \quad$ Disponível: <http://www.anped.org.br/sites/default/files/gt08-2221_int.pdf>. Acesso em: 20 de out. 2018.

RODRIGUES, H. G. Os primeiros socorros na educação física escolar. Revista Científica Multidisciplinar Núcleo do Conhecimento. Ano 1. Vol. 9. pp. 215-234, out./ nov. 2016. Disponível em: <https://www.nucleodoconhecimento.com.br/educacao/os-primeiros-socorros- 
na-educacao-fisica-escolar >. Acesso em: 20 de out. 2018.

SENA, S. P.; RICAS, J.; VIANA, M. R. de A. A percepção dos acidentes escolares Por Educadores do ensino fundamental, Belo Horizonte. Revista Med. Minas Gerais, Belo Horizonte, 2011. Disponível em:

<g/article/view/127/109>. Acesso em: 20 de out. 2018.

SIEBENEICHLER, A.E.M.; HAHN, G.V. Professores da Pré-escola e o agir em Situações de Emergência. Revista Destaques Acadêmicos, Vol. 6, N. 3 -

CCBS/UNIVATES. Lajeado - RS, 2014. Disponível em:

<http://www.univates.br/revistas/index.php/destaques/article/view/424>. Acesso em: $20 \mathrm{de}$ out. 2018.

SILVA, M. B. S. S. Apostila primeiros socorros à criança na escola. Brasil, Vale do Itajaí, p.1-32, set. 2012. Disponível em: <https://www.amavi.org.br/arquivos/amavi/colegiados/codime/2016/Primeiros_Socorros_Proj eto_Unimed\%20Vida_2011_Prevencao_de_Acidentes_Dra_Maria.pdf >. Acesso em: 20 de out. 2018.

SOUZA, A. C. et al. Trânsito como temática interdisciplinar em promoção da saúde. Revista Interdisciplinar de Estudos em Saúde, v. 7, n. 1, p. 187-203, 2018.

SOUZA, C. R. Primeiros Socorros no Ensino Fundamental. 2013. Universidade de Brasília. (Licenciatura) Faculdade UnB Planaltina. Planaltina. Disponível em: <http://bdm.unb.br/bitstream/10483/6031/1/2013_CeciliaReginaDeSouza.pdf >. Acesso em: 20 de out. 2018.

TERASSI M. et al. A percepção de crianças do ensino fundamental sobre parada cardiorrespiratória. SEMINA: Ciências Biológicas e da Saúde, Londrina, V.36, N.1, P.99108, 2015.2 Disponível em: <http://www.uel.br/revistas/uel/index.php/seminabio/article/view/19145>. Acesso em: $20 \mathrm{de}$ out. 2018.

TINOCO V. A.; REIS M. M. T.; FREITAS L. N. O enfermeiro promovendo saúde como educador escolar: atuando em primeiros socorros. Revista Transformar, N.6, P.104-113, 2014.

<http://www.fsj.edu.br/transformar/index.php/transformar/article/view/16>. Acesso em: $20 \mathrm{de}$ out. 2018.

VIEIRA, L. J. E. S.; CARNEIRO, R. C. M. M.; FROTA, M. A.; et al. Ações e possibilidades de prevenção de acidentes com crianças em creches de Fortaleza, Ceará. Scielo. Ciênc. Saúde coletiva vol.14 no.5 Rio de Janeiro Nov./Dec. 2009. Disponível em: $<$ http://www.scielo.br/scielo.php?pid=S1413$81232009000500010 \&$ script=sci_abstract\&tlng=es $>$. Acesso em: 20 de out. 2018. 